\title{
A Hydrologist's Guide to Open Science
}

\author{
Caitlyn A. Hall ${ }^{1}$, Sheila M. Saia ${ }^{2}$, Andrea L. Popp ${ }^{3}$, Nilay Dogulu ${ }^{4}$, Stanislaus J. Schymanski ${ }^{5}$, Niels
} Drost $^{6}$, Tim van Emmerik ${ }^{7}$, Rolf Hut ${ }^{8}$

${ }^{1}$ The Honors College and Biosystems Engineering Department, University of Arizona, Tucson, AZ, United States

$5{ }^{2}$ Department of Biological and Agricultural Engineering, North Carolina State University, Raleigh, NC, United States ${ }^{3}$ Department of Geosciences, University of Oslo, Oslo, Norway

${ }^{4}$ Independent researcher, Ankara, Turkey

${ }^{5}$ Department of Environmental Research and Innovation, Luxembourg Institute of Science and Technology, Luxembourg ${ }^{6}$ Netherlands eScience Center, Amsterdam, Netherlands

$10 \quad{ }^{7}$ Hydrology \& Quantitative Water Management Group, Wageningen University, Wageningen, Netherlands

${ }^{8}$ Water Resources Section, Faculty of Civil Engineering and Geosciences, Delft University of Technology, Delft, Netherlands

Correspondence to: Rolf Hut (r.w.hut@tudelft.nl)

\begin{abstract}
Open, accessible, reusable, and reproducible hydrologic research can have a significant impact on the scientific community and broader society. While more individuals and organizations within the hydrology community are embracing open science practices, technical (e.g., limited coding experience), resource (e.g., open access fees), and social (e.g., fear of being scooped) challenges remain. Furthermore, there are a growing number of constantly evolving open science tools, resources, and initiatives that can seem overwhelming. These challenges and the ever-evolving nature of the open science landscape may seem insurmountable for hydrologists interested in pursuing open science. Therefore, we propose general Open Hydrology Principles to guide individual and community progress toward open science for research and education and the Open Hydrology Practical Guide to improve the accessibility of currently available tools and approaches. We aim to inform and empower hydrologists as they transition to open, accessible, reusable, and reproducible research. We discuss the benefits as well as common open science challenges and how hydrologists can overcome them. The Open Hydrology Principles and Open Hydrology Practical Guide reflect our knowledge of the current state of open hydrology; we recognize that recommendations and suggestions will evolve and expand with emerging open science infrastructures, workflows, and research experiences. Therefore, we encourage hydrologists all over the globe to join in and help advance open science by contributing to the living version of this document and by sharing open hydrology resources in the community-supported
\end{abstract} repository (https://open-hydrology.github.io).

\section{Motivation for Open Hydrology}

Hydrologic research intersects various Earth sciences (e.g., climatology, geology, ecology) and social science (e.g., policy and public health) to tackle pressing environmental and societal challenges. Further, hydrologic research often incorporates qualitative and quantitative data from numerical models, laboratory techniques, field observations, and stakeholder surveys, 
35 all of which rely on separate sets of assumptions, standards, and methods. When combined, the interdisciplinary nature and wide range of methods used in hydrology can result in research that is neither accessible nor usable by the scientific community and relevant stakeholders. A recent study found that only $1 \%$ of hydrology papers were fully reproducible (Stagge et al., 2019). Therefore, hydrologists must evolve to ensure their data and research process is transparent and reproducible. Doing so will strengthen their contribution to hydrologic research practices, educational resources, knowledge base, and applications, as well as educational resources, science, communication, societal engagement, and public trust (Cudennec et al., 2020).

Open science offers an established framework for hydrologists to purposefully document and widely share scientific research that is accessible to scientists and the public, as to improve their work's transparency and reproducibility. Open science is a movement that is transforming the nature of research design and conduct, as well as how experts and non-experts alike build upon and learn from each other's scientific work. Researchers and stakeholders are recognizing open science as the future of hydrologic research, scientific communication, and education (e.g., (Baker et al., 2020; ECMWF moves towards a policy of open data, 2021; UNESCO, 2021; WMO Data Conference - Outcome Material, 2021). Community-driven efforts within the field of hydrology have cemented the demand and necessity for open science, specifically referred to as open hydrology (Blumenthal et al., 2014; de Vos et al., 2020; Ferrari et al., 2018; Mwelwa et al., 2020; Powers and Hampton, 2019; Tai and

50 Robinson, 2018; Zuiderwijk and Hinnant, 2019), research projects (e.g.(Beck et al., 2020; Lowndes et al., 2017), and conferences (e.g., (OpenAIRE's Mission and Vision, 2021). Likewise, many organizations have begun to provide support, conference sessions, online repositories, and educational training opportunities to overcome challenges and support researchers as they transition to open hydrology (Baker et al., 2020). Furthermore, several hydrology journals now require data and analyses to be made publicly available upon article publication (Rosenberg and Watkins, 2018; American

55 Geophysical Union (AGU), 2019). Table 1 provides a summary of the various hydrology-focused efforts towards open science (e.g., academic articles, GitHub pages, web platforms, etc.).

Despite general calls and efforts to support open science, practical guidance on steps hydrologists can take to incorporate open principles in their research is limited. The objective of this paper is to introduce the Open Hydrology Principles and Open Hydrology Practical Guide to help hydrologists take actionable steps towards open science. We focus on four major

60 research stages: (1) research process and approach, (2) data collection and analysis, (3) software development and use, and (4) publishing. For each stage, we discuss guiding principles for meaningful engagement in open hydrology and we provide practical steps to answer how to engage in openness. Finally, we address potential challenges by walking through "What if...?" questions that hydrologists might encounter when pursuing open science (Appendix A). Herein, we draw on existing open science research, efforts, and experiences in hydrology as well as in disciplines outside of hydrology that have made

65 significant progress toward open science. The Open Hydrology Principles and Open Hydrology Practical Guide introduced here are available online at open-hydrology.github.io. This website provides a platform to facilitate continued discussion and evolution of open hydrology presented in this article (i.e., serve as a living document), highlight emerging open hydrology resources and educational opportunities, and serve as a meeting point to connect open hydrologists. We invite everyone to 
contribute to the discussion, share resources and experiences, and work towards incorporating open science principles in all stages of their hydrology research.

\section{Open Hydrology Principles \& Open Hydrology Practical Guide}

Open hydrologists, including those who are beginning their journey to those who are more experienced, can use the Open Hydrology Principles and Open Hydrology Practical Guide to expand their open hydrology practice. Adoption of these open hydrology principles is not restricted to a specific stage of research. Furthermore, these principles can and should be

implemented throughout a research project's timeline. Transitioning to fully open hydrology research will likely remain a work in progress and cannot happen overnight. Hydrologists will need to work within current logistical, legal, financial, cultural, and other constraints. In this section, we outline four guiding principles corresponding to four major hydrological research stages, illustrated in Figure 1. Each guiding principle is followed by a practical guide to help hydrologists apply these principles. We have also included a discussion on anticipating and overcoming challenges to practicing open hydrology (Appendix A), which can be used for educational purposes, as well as spur discussion and action in open hydrologists of all levels and in various settings from classrooms to lab groups to workshops.

Principle 1 - Open Research Process and Approach: Open hydrologists intentionally plan for, describe, and share the entire research process and approach from motivation to the final product.

Research process and approach includes openly discussing stakeholder engagement practices and agreements, failed methods, negative results, use of public datasets, and feedback from third parties. Openly sharing a well-documented research process and approach in hydrology will improve the efficacy of internal research and knowledge exchange and give critical insight to aspiring researchers that may not be fully captured in journal articles. Furthermore, sharing the entire research process and approach is critical for the hydrology field because research applications directly impact society (e.g., water management, climate model simulations). Thus, open hydrologists must ensure their research is accessible to the science community and the general public while adhering to ethical standards and respecting the goals and wishes of their collaborators. We encourage the use of non-proprietary methods, tools, and resources whenever possible.

\section{Practical Guide to Open Research Process and Approach}

In hydrology, published studies that allow the reader to follow every step of the work, from motivation to publication, remain scarce. Although results are the main focus of a paper, sharing the entire research process and approach (e.g., failed attempts and lessons learned that impacted research outcomes) alongside the paper can improve the impact and openness of research (Lowndes et al., 2017; Colavizza et al., 2020). We suggest including a reasonable explanation of why certain data and methods were chosen and how they were used in the main text of journal articles or an appendix using accessible language. Open hydrologists can maximize openness by minimizing the use of jargon in all materials such that experts and non-experts alike are able to understand and reproduce the research and underlying assumptions. For example, words 
common in hydrology like 'dam' and 'flood' can have different meanings between experts and non-experts (Venhuizen et al., 2019). Open hydrologists can consider getting feedback on the accessibility of research process and approach description by sharing drafts with collaborators and stakeholders.

Perceptual models are in-depth descriptions or visualizations that represent process understanding; qualitative and quantitative data incorporation; field-, lab-, or computer-based methods and protocols; and project stages, also known as a workflow model (Enemark et al., 2019; Wagener et al., 2020). Perceptual models help researchers decide and describe which methods are most appropriate to address the study objective based on underlying assumptions. Consequently, perceptual models will vary by researcher, information, and resource availability. By including accessible perceptual models, researchers can communicate differences in the interpretation and understanding of hydrologic systems while identifying dominant hydrologic processes across scales and experiment types. Moreover, such models allow to explicitly handle

110 uncertainties and failures during the research process and provide a coherent picture of the entire research process to experts and non-experts (Wagener et al., 2020).

Given the important societal and policy implications of hydrologic research, it is important for open hydrologists to codevelop data management plans, research focus, and research dissemination plans alongside stakeholders as early as possible in the research process. Stakeholders may include fellow researchers, industry professionals, non-profit organizations,

115 government officials, communities, members of the public, and other parties that have an interest in hydrologic research. Engagement and co-development with stakeholders are still limited in the field of hydrology. For example, a global survey found that $87 \%$ of climate research that engaged Indigenous communities was extractive; communities had minimal participation or decision-making authority in the researcher-stakeholder relationship (David-Chavez and Gavin, 2018). Consequently, we suggest incorporating FAIR (Wilkinson et al., 2016; Garcia et al., 2020) and CARE (Carroll et al., 2020;

120 Walter et al., 2020) data standards into open hydrology research. FAIR data standards were developed to improve machine readability of data and ultimately increase research reproducibility. CARE data standards were developed by Indigenous scholars to advance data governance and data sovereignty. Setting up guidelines on how open hydrologists will ethically and respectfully engage with relevant stakeholders in their research approach and process is especially important when codeveloping and conducting community science or citizen science (Robinson et al., 2018; Walker et al., 2021).

125 Principle 3 - Open Software Development and Use: Open hydrologists test, archive, document, and version control their research code and software using standard open-source software protocols and accessible documentation language.

Hydrologic research often relies on the use of computational models and research software, which must be archived with appropriate documentation and publicly accessible for verifiability and reproducibility of results. Research software is any

130 code or program used to compile, filter, and process data, create model simulations, and generate data tables or plots. This includes compiled programs, stand-alone and embedded scripts (e.g., in spreadsheets), and computational notebooks (e.g., Jupyter notebooks, RMarkdown documents). Open hydrologists document and describe code, software versions, and 
descriptions of each variable name, meaning, and unit when developing software. Whenever possible, open hydrology software builds on existing open-source software and programming languages (e.g., Python and R) to avoid excessive licensing and setup costs for anyone trying to use these models.

To prevent duplication of failed attempts and increase accessibility and reproducibility, it is crucial to document the complete version history of software development in a clear and comprehensible way using standardized version tracking and version control tools (e.g., Git and SVN). This is particularly important in hydrology, which relies heavily on testing continuous adaptations of existing models as new data becomes available. Transparent version control, software documentation, software guides, and software unit tests are all prerequisites to producing reliable hydrologic model outputs, including predictions of future water resource availability and hydrologic risk, among others. For software licensing and publishing, see Principle 4.

\section{Practical Guide to Open Code and Software Use and Development}

Open platforms offer an effective way for open hydrologists to develop and use research software by building upon software

created by others and getting community support. Open hydrologists can use open-source coding languages (e.g., R and Python) and open-source software (e.g., QGIS) to wrangle, analyze, and share their research findings. Repositories such as GitHub, GitLab, Bitbucket, and language-specific repositories such as CRAN and PyPI are treasure troves of software, often solving a large part of your problem. Using these public and open repositories saves you time and allows others to make use of your software more easily, help you improve it, and in turn build on it for your research.

150 In addition to open-source coding languages and software, hydrologists can incorporate open-source version control system (e.g., Git) into their workflows to capture and manage changes made to code and research. Additionally, file duplication and mistakenly overwriting previous work can be prevented, while allowing others to trace the progression of code, track issues, and collaborate (Perez-Riverol et al., 2016; Lowndes et al., 2017; Bryan, 2018). While, the command-line application form of version control systems can pose a steep learning curve, graphical user interfaces exist and public repositories (e.g., Git Desktop, Git Cola, and GitKraken) offer easy-to-use interfaces, helpful documentation, and tutorials. Various courses are available through the Carpentries (e.g., version control with Git) to help you get started using Git and online Git collaboration platforms like GitHub and GitLab (The Carpentries, 2021). These public repositories facilitate collaborative software development, issue tracking, detailed documentation of modeling decisions, and project management.

The simplest way of creating code documentation is often to include it with the software in some form, but technical documentation can also be hosted on Readthedocs. Variables need to be clearly defined and documentation must include the units directly in the code or in an associated appendix. Various open-source programming languages offer ways to generate technical documentation from the code itself (e.g., pydoc for Python and roxygen for R).

Even if the source code of all packages used in a research project is publicly available, it may be difficult to reproduce an analysis if the versions of the packages are not known, or if the operating system version is not compatible. For this reason, several methods for sharing a computational environment have been created in recent years. Software containers (e.g., 
Docker) can help to share a complete computational environment, including the operating system and necessary packages with your code (Nüst et al., 2020). Open-source programming languages can also offer specific tools to keep track of versions (e.g., renv and Docker for R). Other open-source software platforms of interest to open hydrologists may include, binder, which reproduces a computational Jupyter notebook with a single click from a software repository. Additionally, Renkulab allows version control of data, software, and computational environments from within a single platform. Renkulab also enables transparent tracking of the lineage of research results, from external data sources to final figures in articles.

When using a GitHub repository, automatic code and software testing can be implemented using continuous integration software (e.g., Travis CI), which runs pre-designed tests and workflows and checks for errors. Tests and workflows may include comparing model results to a reference dataset and alerting the user to changes in the model results or checking whether recent changes made to one section of code will cause errors in downstream code.

Principle 4 - Open Publishing: Open hydrologists publish all components of their research on citable platforms and in journals that follow ethical standards and are accessible to both the research community and general public.

Research sharing is pivotal to enabling the transferability of hydrologic insights and building on existing hydrology research. Thus, we highly suggest open hydrologists publish all research components using a permissive license that allows editing and sharing derivative works with both scientists and the general public. There are, however, special cases where information (e.g., from water utility providers or governmental agencies) cannot be shared publicly due to privacy and safety (i.e., national security) reasons. If this is the case, the potential reproducibility limitations associated with these data need to be considered and openly discussed.

How and where open hydrologists choose to publish their work is crucial for supporting high global standards for the accessibility, preservation, and reproducibility of hydrology research. Whenever possible, open hydrologists publish all their results (including articles, data, software, etc.) in publicly accessible repositories and journals with transparent connections between each (i.e., adding a link to the publication that points readers to the associated data and analysis code). It is also important that publishers and libraries have the appropriate infrastructure in place for bibliographic tracking, transparent cross-referencing between hosted research objects, and appropriate crediting of researchers for their contributions.

\section{Practical Guide to Open Science Publishing}

There are three primary open access (OA) journal publication models: (1) gold OA or diamond OA, which provides free final typeset article access to everyone, (2) hybrid OA, which involves subscription-based journals that charge an additional fee for making a particular article freely accessible, and (3) green OA, in which the authors can self-archive the accepted, non-typeset authors' version of an article (i.e., a postprint) in a suitable repository after the journal's embargo period. Gold OA journals charge no subscription fees, but typically require an article processing charge (APC) fee. Diamond OA journals do not charge an APC and are usually funded by non-profit organizations, governments, societies, or other revenue streams. The copyright for articles published in gold or diamond OA journals stays with the authors, whereas hybrid OA may provide 
the option that authors pay for obtaining the copyright on an individual article (in its final, typeset version) and for making it OA on the publisher's website. There are some exceptions to this for lead and/or corresponding authors working for government agencies where the general public is directly supporting their research; however, authors must check with the specific copyright policy of the journal for more details. Hybrid publishing has been criticized because the scientific community typically pays twice - once for the journal subscription and once for individual article OA fees (Double Dipping in Hybrid Open Access - Chimera or Reality? - JuSER, 2020; Pinfield et al., 2016).

There are numerous aspects to consider when choosing a journal beyond OA options. These include considering the article license type, the archiving services available, the financial policies for review and publication, and the release requirements for data, code, and software. Responsibility for moving towards open hydrology lies with the author, editors, and reviewers. Reviewers can promote proper citing and acknowledgment of data and code sources by requesting that these be made publicly available when they are missing from the submitted paper. To this end, reviewers can start by checking if the authors of the article adhere to the journal's open science standards. If this is not the case, the reviewer can indicate clearly in their review that the work does not comply and provide constructive feedback for how these standards can be met. If the journal does not have clearly defined open science standards, reviewers can request and provide steps on how authors can adhere to open science practices to ensure that the submitted work is reproducible. Likewise, reviewers can initiate discussions with the editor and highlight how the importance of clear open science standards provides guidance to authors and generally improves the quality, transparency, and reproducibility of submitted articles.

215 Articles that have not yet undergone peer-review but are published publicly (i.e., preprints) can be shared at any stage of the open hydrology project (Saia, 2019). Preprints are a good opportunity for authors to share and get feedback from a more diverse set of reviewers while retaining control of the research publication timeline (Schloss, 2017; Saia, 2019). Before posting a preprint, we suggest researchers check with their target journal about the acceptability of published pre-prints. Many journals will allow you to submit an article that has been posted as a preprint, but some will not. Visit Sherpa Romeo or the Journal Checker Tool (provided by cOAlition S) to find out about preprint policies, copyrights, and open access archiving policies from various publishers and journals.

Another important aspect related to OA publishing is the license attached to an article. Creative Commons licenses (e.g., CCBY) are widespread, but some publishers choose more restrictive versions, indicated by additions such as NC ("for noncommercial use") or ND ("No derivatives or adaptations of the work are permitted"). ND licenses hamper re-use of the published work since extracting figures or tables from the paper is not allowed. Besides the article itself, it is important to ensure that data and code have a permissive license (e.g., CC-BY) for legal reuse. For software, we suggest the authors start by declaring a permissive license because it improves transparency and reduces downstream licensing conflicts. However, software developers should be aware of upstream licenses and whether those may impact their ability to choose an opensource license. See Choose a License for help on selecting suitable licenses. Text, images, videos, photos, or other media created during or associated with a hydrologic project can be licensed using a CC-BY license to ensure creator attribution (i.e., the BY of CC-BY). 
Data and code associated with an article must be cited in the article and published in a long-term repository, with a separate Digital Object Identifier (DOI) and a permissive open-source license (e.g., re3data). This facilitates citations and allows for re-use and modification of work. To ensure that researchers providing software and data get properly credited for their efforts, third-party data or software used by others must be cited accordingly. Unlike data, source code for research software rarely requires much storage and can be shared quite easily (see Principle 3). The problematic aspect of software development is ensuring that it is available and usable for decades. Journals often allow software to be published as a supplement, which is most suitable for scripts and Jupyter notebooks created specifically for a publication. More general-use software should be published and archived in a public repository with a separate DOI. One prime example is Zenodo-a free service for hosting data and software that offers long-term ( 20 year) storage, integration with GitHub, and provides a DOI for each software version deposited there. These DOIs can be used as references in publications and clearly defines the software version used.

\section{Summary and Outlook}

Open, accessible, reusable, and reproducible hydrologic research will have the largest equitable impact on the scientific 245 community and broader society. Funding agencies, publishers, and hydrologic organizations are increasingly requiring hydrologists to adopt open science practices. We wrote 'A Hydrologist's Guide to Open Science' to facilitate the transition to fully open science within hydrology, for hydrologists at the forefront of this movement, and those transitioning their research to fully open science. This work introduces four guiding Open Hydrology Principles referring to each of the four main research stages: (1) research process and approach, (2) data collection and analyses, (3) software development and use, and (4) publishing. For each principle, we provided actionable steps (i.e., the Open Hydrology Practical Guide) on how to become a more open hydrologist.

Hydrologists intending to implement the advice given here will, undoubtedly, run into challenges along their path. We identified and addressed twelve challenges in five scenarios that cover various hydrology career stages (Appendix A). Researchers interested in open hydrology can use these scenarios to roleplay common challenges and brainstorm strategies with colleagues (e.g., in your lab's or department's journal club) to overcome these challenges on their way to becoming an as-open-as-possible hydrologist.

While approaches and methods related to open science are in constant development, the Open Hydrology Principles will guide us in the future. The Open Hydrology Practical Guide is written based on currently available paradigms, tools, policies, and experiences; it will be updated and replaced by guidance as the state of hydrology and open science policies change. Therefore, we created open-hydrology.github.io - a living version of this article to build a supportive and collaborative open science community within the field of hydrology.

Getting to the point where a majority (or more) of hydrologists participate in open hydrology will take time and effort. These efforts will be driven by individual hydrologists implementing openness as well as by organizational and governmental 
policies that incentivize open science. This step-by-step process must be regarded as a valuable contribution to hydrology and systemically supported by scientific institutions and beyond. Only then can the entire hydrology community really come together, build on one another's work, strengthen hydrologic knowledge, and maximize the benefits of hydrologic research to the whole of society.

\section{Acknowledgements}

We would like to thank Lieke Melsen, Thorsten Wagener, and others for the initial discussions and inspiration to write this paper. A. L. Popp is supported by the University of Oslo. S. Schymanski is supported by the Luxembourg National Research Fund (FNR) ATTRACT Programme (A16/SR/11254288); T. van Emmerik is supported by the Veni Research Program The River Plastic Monitoring Project (\#18211), which is (partly) financed by the Dutch Research Council (NWO). There is no code nor data associated with this article. The authors have no conflicts of interest to declare. Please endorse the Open Hydrology Principles, contribute to the open hydrology discussion, and access a living version (i.e., up-to-date version) of the Open Hydrology Principles and Practical Guide online at https://open-hydrology.github.io.

CRediT Contributions Statement: All authors contributed to the conceptualization of this article and participated in writing the original draft, as well as draft review and editing. C. A. Hall administered this project and N. Drost created the GitHub repository and living version website.

\section{References}

280 Addor, N., Do, H. X., Alvarez-Garreton, C., Coxon, G., Fowler, K., and Mendoza, P. A.: Large-sample hydrology: recent progress, guidelines for new datasets and grand challenges, Hydrological Sciences Journal, 65, 712-725, https://doi.org/10.1080/02626667.2019.1683182, 2020.

Allen, C. and Mehler, D. M. A.: Open science challenges, benefits and tips in early career and beyond, PLOS Biology, 17, e3000246, https://doi.org/10.1371/journal.pbio.3000246, 2019.

285 American Geophysical Union (AGU): Position Statement on Data: Supporting Data as a World Heritage, 2019.

Añel, J. A., García-Rodríguez, M., and Rodeiro, J.: Current status on the need for improved accessibility to climate models code, 14, 923-934, https://doi.org/10.5194/gmd-14-923-2021, 2021.

General Data Protection Regulation (GDPR): https://gdpr-info.eu/, last access: 21 July 2021.

Podcasts: https://www.orion-openscience.eu/publications/training-materials/201902/podcasts, last access: 21 July 2021.

About FOSTER: https://www.fosteropenscience.eu/about, last access: 19 March 2021.

Educational Resources for Hydrology \& Water Resources | CUAHSI HydroShare: https://www.hydroshare.org/resource/148b1ce4e308427ebf58379d48a17b91/, last access: 21 July 2021. 
GitHub - Open-Environmental-Science/awesome-open-hydrology: https://github.com/Open-EnvironmentalScience/awesome-open-hydrology, last access: 21 July 2021.

295 Learner Profiles: http://software-carpentry.org//audience/, last access: 21 July 2021.

ropensci/Hydrology: CRAN Hydrology: https://github.com/ropensci/Hydrology, last access: 21 July 2021.

The Carpentries: https://github.com/carpentries, last access: 21 July 2021.

UNESCO: https://unesdoc.unesco.org/ark:/48223/pf0000374837, last access: 19 March 2021.

WMO Data Conference - Outcome Material: https://meetings.wmo.int/WMO-DataConference/SitePages/Outcome\%20Material.aspx, last access: 19 March 2021.

Young Hydrologic Society (YHS): https://github.com/hydrosoc, last access: 21 July 2021.

Baker, L., Cristea, I. A., Errington, T. M., Jaśko, K., Lusoli, W., MacCallum, C. J., Parry, V., Pérignon, C., Šimko, T., and Winchester, C.: Reproducibility of scientific results in the EU: scoping report, edited by: Lusoli, W., European Commission, Luxembourg, 32 pp., 2020.

305 Beck, M. W., O'Hara, C., Stewart Lowndes, J. S., D. Mazor, R., Theroux, S., J. Gillett, D., Lane, B., and Gearheart, G.: The importance of open science for biological assessment of aquatic environments, 8, e9539, https://doi.org/10.7717/peerj.9539, 2020.

Blöschl, G., Bárdossy, A., Koutsoyiannis, D., Kundzewicz, Z. W., Littlewood, I., Montanari, A., and Savenije, H.: Joint Editorial—On the future of journal publications in hydrology, 59, 955-958, https://doi.org/10.1080/02626667.2014.908041, 2014.

Blumenthal, M. B., Bell, M., del Corral, J., Cousin, R., and Khomyakov, I.: IRI Data Library: enhancing accessibility of climate knowledge, Earth Perspectives, 1, 19, https://doi.org/10.1186/2194-6434-1-19, 2014.

Borregaard, M. K. and Hart, E. M.: Towards a more reproducible ecology, Ecography, 39, 349-353, https://doi.org/10.1111/ecog.02493, 2016.

315 Bryan, J.: Excuse Me, Do You Have a Moment to Talk About Version Control?, The American Statistician, 72, 20-27, https://doi.org/10.1080/00031305.2017.1399928, 2018.

Carroll, S. R., Garba, I., Figueroa-Rodríguez, O. L., Holbrook, J., Lovett, R., Materechera, S., Parsons, M., Raseroka, K., Rodriguez-Lonebear, D., Rowe, R., Sara, R., Walker, J. D., Anderson, J., and Hudson, M.: The CARE Principles for Indigenous Data Governance, 19, 43, https://doi.org/10.5334/dsj-2020-043, 2020.

320 Colavizza, G., Hrynaszkiewicz, I., Staden, I., Whitaker, K., and McGillivray, B.: The citation advantage of linking publications to research data, PLoS ONE, 15, e230416, https://doi.org/10.1371/journal.pone.0230416, 2020.

Crochemore, L., Isberg, K., Pimentel, R., Pineda, L., Hasan, A., and Arheimer, B.: Lessons learnt from checking the quality of openly accessible river flow data worldwide, 65, 699-711, https://doi.org/10.1080/02626667.2019.1659509, 2020.

HydroShare: https://www.hydroshare.org/landingPage/, last access: 21 July 2021. 
325 Cudennec, C., Lins, H., Uhlenbrook, S., and Arheimer, B.: Editorial - Towards FAIR and SQUARE hydrological data, Hydrological Sciences Journal, 65, 681-682, https://doi.org/10.1080/02626667.2020.1739397, 2020.

David-Chavez, D. M. and Gavin, M. C.: A global assessment of Indigenous community engagement in climate research, Environ. Res. Lett., 13, 123005, https://doi.org/10.1088/1748-9326/aaf300, 2018.

Dixon, H., Sandström, S., Cudennec, C., Lins, H. F., Abrate, T., Bérod, D., Chernov, I., Ravalitera, N., Sighomnou, D., and 330 Teichert, F.: Intergovernmental cooperation for hydrometry - what, why and how?, 0, 1-15, https://doi.org/10.1080/02626667.2020.1764569, 2020.

Enemark, T., Peeters, L. J. M., Mallants, D., and Batelaan, O.: Hydrogeological conceptual model building and testing: A review, Journal of Hydrology, 569, 310-329, https://doi.org/10.1016/j.jhydrol.2018.12.007, 2019.

EOSC Podcast Special: Making Open Science FAIR For Researchers: https://www.eoscsecretariat.eu/news-opinion/eoscpodcast-special-making-open-science-fair-researchers, last access: 21 July 2021.

European Geosciences Union: \#shareEGU20: open and FAIR your science, n.d.

Ferrari, T., Scardaci, D., and Andreozzi, S.: The Open Science Commons for the European Research Area, in: Earth Observation Open Science and Innovation, edited by: Mathieu, P.-P. and Aubrecht, C., Springer International Publishing, Cham, 43-67, https://doi.org/10.1007/978-3-319-65633-5_3, 2018.

340 Garcia, L., Batut, B., Burke, M. L., Kuzak, M., Psomopoulos, F., Arcila, R., Attwood, T. K., Beard, N., Carvalho-Silva, D., and Dimopoulos, A. C.: Ten simple rules for making training materials FAIR, 16, e1007854, 2020.

Data protection GDPR: https://gemstat.org/contact/data-protection-gdpr/, last access: 21 July 2021.

Gleeson, T.: A buffet of new resources for teaching hydrology and water resources!, EGU Blogs: Water Underground, 2020.

Hampton, S. E., Anderson, S. S., Bagby, S. C., Gries, C., Han, X., Hart, E. M., Jones, M. B., Lenhardt, W. C., MacDonald, 345 A., Michener, W. K., Mudge, J., Pourmokhtarian, A., Schildhauer, M. P., Woo, K. H., and Zimmerman, N.: The Tao of open science for ecology, Ecosphere, 6, art120, https://doi.org/10.1890/ES14-00402.1, 2015.

Hughes, D. A., Heal, K. V., and Leduc, C.: Improving the visibility of hydrological sciences from developing countries, 59, 1627-1635, https://doi.org/10.1080/02626667.2014.938653, 2014.

Hutton, C., Wagener, T., Freer, J., Han, D., Duffy, C., and Arheimer, B.: Most computational hydrology is not reproducible, so is it really science?, 52, 7548-7555, https://doi.org/10.1002/2016WR019285, 2016.

ECMWF moves towards a policy of open data: https://www.ecmwf.int/en/about/media-centre/news/2020/ecmwf-movestowards-policy-open-data, last access: 19 March 2021.

Laine, H.: Afraid of Scooping - Case Study on Researcher Strategies against Fear of Scooping in the Context of Open Science, 16, 29, https://doi.org/10.5334/dsj-2017-029, 2017.

355 Lowndes, J. S. S., Best, B. D., Scarborough, C., Afflerbach, J. C., Frazier, M. R., O’Hara, C. C., Jiang, N., and Halpern, B. S.: Our path to better science in less time using open data science tools, 1, 1-7, https://doi.org/10.1038/s41559-017-0160, 2017.

OpenAIRE's Mission and Vision: https://www.openaire.eu/mission-and-vision, last access: 19 March 2021. 
https://doi.org/10.5194/hess-2021-392

Preprint. Discussion started: 2 August 2021

(c) Author(s) 2021. CC BY 4.0 License.

Melsen, L. A., Torfs, P. J. J. F., Uijlenhoet, R., and Teuling, A. J.: Comment on "Most computational hydrology is not reproducible, so is it really science?" by Christopher Hutton et al., 53, 2568-2569, https://doi.org/10.1002/2016WR020208, 2017.

Michener, W. K.: Ecological data sharing, Ecological Informatics, 29, 33-44, https://doi.org/10.1016/j.ecoinf.2015.06.010, 2015 .

Mislan, K. A. S., Heer, J. M., and White, E. P.: Elevating The Status of Code in Ecology, Trends in Ecology \& Evolution, 31, 4-7, https://doi.org/10.1016/j.tree.2015.11.006, 2016.

Double Dipping in Hybrid Open Access - Chimera or Reality? - JuSER: https://juser.fzjuelich.de/record/190180/files/Double\%20http://juser.fz-juelich.de/record/190180Dipping.pdf, last access: 1 October 2020.

Mukuyu, P., Lautze, J., Rieu-Clarke, A., Saruchera, D., and McCartney, M.: The devil's in the details: data exchange in transboundary waters, 45, 884-900, https://doi.org/10.1080/02508060.2020.1850026, 2020.

370 Mwelwa, J., Boulton, G., Wafula, J. M., and Loucoubar, C.: Developing Open Science in Africa: Barriers, Solutions and Opportunities, CODATA, 19, 31, https://doi.org/10.5334/dsj-2020-031, 2020.

Nüst, D., Sochat, V., Marwick, B., Eglen, S. J., Head, T., Hirst, T., and Evans, B. D.: Ten simple rules for writing Dockerfiles for reproducible data science, 16, e1008316, https://doi.org/10.1371/journal.pcbi.1008316, 2020.

Pecora, S. and Lins, H. F.: E-monitoring the nature of water, Hydrological Sciences Journal, 65, 683-698, https://doi.org/10.1080/02626667.2020.1724296, 2020.

Perez-Riverol, Y., Gatto, L., Wang, R., Sachsenberg, T., Uszkoreit, J., Leprevost, F. da V., Fufezan, C., Ternent, T., Eglen, S. J., Katz, D. S., Pollard, T. J., Konovalov, A., Flight, R. M., Blin, K., and Vizcaíno, J. A.: Ten Simple Rules for Taking Advantage of Git and GitHub, PLoS Comput Biol, 12, e1004947, https://doi.org/10.1371/journal.pcbi.1004947, 2016.

Pinfield, S., Salter, J., and Bath, P. A.: The "total cost of publication" in a hybrid open-access environment: Institutional

approaches to funding journal article-processing charges in combination with subscriptions, 67, 1751-1766, 2016.

Powers, S. M. and Hampton, S. E.: Open science, reproducibility, and transparency in ecology, Ecol Appl, 29, https://doi.org/10.1002/eap.1822, 2019.

Quinn, N., Blöschl, G., Bárdossy, A., Castellarin, A., Clark, M., Cudennec, C., Koutsoyiannis, D., Lall, U., Lichner, L., Parajka, J., Peters-Lidard, C. D., Sander, G., Savenije, H., Smettem, K., Vereecken, H., Viglione, A., Willems, P., Wood, A., 385 Woods, R., Xu, C., and Zehe, E.: Invigorating Hydrological Research Through Journal Publications, Water Resour. Res., 56, 2018WR024053, https://doi.org/10.1029/2018WR024053, 2020.

Reichman, O. J., Jones, M. B., and Schildhauer, M. P.: Challenges and Opportunities of Open Data in Ecology, Science, 331, 703-705, https://doi.org/10.1126/science.1197962, 2011.

Robinson, L. D., Cawthray, J. L., West, S. E., Bonn, A., and Ansine, J.: Ten principles of citizen science, in: Citizen science: Innovation in open science, society and policy, UCL Press, 27-40, 2018.

Rosenberg, D. E. and Watkins, D. W.: New Policy to Specify Availability of Data, Models, and Code, J. Water Resour. Plann. Manage., 144, 01618001, https://doi.org/10.1061/(ASCE)WR.1943-5452.0000998, 2018.

Saia, S.: An Introduction to Preprints for Early Career Hydrologists, Young Hydrologic Society, 2019. 
https://doi.org/10.5194/hess-2021-392

Preprint. Discussion started: 2 August 2021

(c) Author(s) 2021. CC BY 4.0 License.

Schaefli, B.: Open teaching to navigate hydrology: how ready are we?, EGU Blogs: Hydrological Sciences, 2021.

Schloss, P. D.: Preprinting Microbiology, mBio, 8, mBio.00438-17, e00438-17, https://doi.org/10.1128/mBio.00438-17, 2017.

Slater, L. J., Thirel, G., Harrigan, S., Delaigue, O., Hurley, A., Khouakhi, A., Prosdocimi, I., Vitolo, C., and Smith, K.: Using R in hydrology: a review of recent developments and future directions, 23, 2939-2963, https://doi.org/10.5194/hess23-2939-2019, 2019.

Sprenger, M.: When the students are gone: Transition to online teaching, EGU Blogs: Hydrological Sciences, 2020.

Stagge, J. H., Rosenberg, D. E., Abdallah, A. M., Akbar, H., Attallah, N. A., and James, R.: Assessing data availability and research reproducibility in hydrology and water resources, 6, 190030, https://doi.org/10.1038/sdata.2019.30, 2019.

Tai, T. C. and Robinson, J. P. W.: Enhancing Climate Change Research With Open Science, Front. Environ. Sci., 6, 115, https://doi.org/10.3389/fenvs.2018.00115, 2018.

405 Turner, B., Hill, D. J., and Caton, K.: Cracking “Open” Technology in Ecohydrology, in: Forest-Water Interactions, vol. 240, edited by: Levia, D. F., Carlyle-Moses, D. E., Iida, S., Michalzik, B., Nanko, K., and Tischer, A., Springer International Publishing, Cham, 3-28, https://doi.org/10.1007/978-3-030-26086-6_1, 2020.

Van Loon, A. F.: Online teaching in courses related to climate risk, drought, water resources and sustainability, Hydrological extremes@Amsterdam, 2020.

410 Venhuizen, G. J., Hut, R., Albers, C., Stoof, C. R., and Smeets, I.: Flooded by jargon: how the interpretation of water-related terms differs between hydrology experts and the general audience, 23, 393-403, https://doi.org/10.5194/hess-23-393-2019, 2019.

de Vos, M. G., Hazeleger, W., Bari, D., Behrens, J., Bendoukha, S., Garcia-Marti, I., van Haren, R., Haupt, S. E., Hut, R., Jansson, F., Mueller, A., Neilley, P., van den Oord, G., Pelupessy, I., Ruti, P., Schultz, M. G., and Walton, J.: Open weather and climate science in the digital era, Geosci. Commun., 3, 191-201, https://doi.org/10.5194/gc-3-191-2020, 2020.

Wagener, T., Gleeson, T., Coxon, G., Hartmann, A., Howden, N., Pianosi, F., Rahman, S., Rosolem, R., Stein, L., and Woods, R.: On doing large-scale hydrology with Lions: Realising the value of perceptual models and knowledge accumulation, EarthArXiv, https://doi.org/10.31223/osf.io/zdy5n, 2020.

Walker, D. W., Smigaj, M., and Tani, M.: The benefits and negative impacts of citizen science applications to water as experienced by participants and communities, 8, e1488, https://doi.org/10.1002/wat2.1488, 2021.

Walter, M., Kukutai, T., Carroll, S. R., and Rodriguez-Lonebear, D. (Eds.): Indigenous Data Sovereignty and Policy, 1st ed., Routledge, London, 244 pp., 2020.

Wang, X., Liu, C., Mao, W., and Fang, Z.: The open access advantage considering citation, article usage and social media attention, Scientometrics, 103, 555-564, https://doi.org/10.1007/s11192-015-1547-0, 2015.

425 Wilkinson, M. D., Dumontier, M., Aalbersberg, Ij. J., Appleton, G., Axton, M., Baak, A., Blomberg, N., Boiten, J.-W., da Silva Santos, L. B., Bourne, P. E., Bouwman, J., Brookes, A. J., Clark, T., Crosas, M., Dillo, I., Dumon, O., Edmunds, S., Evelo, C. T., Finkers, R., Gonzalez-Beltran, A., Gray, A. J. G., Groth, P., Goble, C., Grethe, J. S., Heringa, J., ’t Hoen, P. A. C., Hooft, R., Kuhn, T., Kok, R., Kok, J., Lusher, S. J., Martone, M. E., Mons, A., Packer, A. L., Persson, B., Rocca-Serra, P., Roos, M., van Schaik, R., Sansone, S.-A., Schultes, E., Sengstag, T., Slater, T., Strawn, G., Swertz, M. A., Thompson, 
https://doi.org/10.5194/hess-2021-392

Preprint. Discussion started: 2 August 2021

(c) Author(s) 2021. CC BY 4.0 License.

430 M., van der Lei, J., van Mulligen, E., Velterop, J., Waagmeester, A., Wittenburg, P., Wolstencroft, K., Zhao, J., and Mons, B.: The FAIR Guiding Principles for scientific data management and stewardship, Sci Data, 3, 160018, https://doi.org/10.1038/sdata.2016.18, 2016.

Zipper, S. C., Stack Whitney, K., Deines, J. M., Befus, K. M., Bhatia, U., Albers, S. J., Beecher, J., Brelsford, C., Garcia, M., Gleeson, T., O’Donnell, F., Resnik, D., and Schlager, E.: Balancing Open Science and Data Privacy in the Water Sciences,

Water Resour. Res., 55, 5202-5211, https://doi.org/10.1029/2019WR025080, 2019.

Zuiderwijk, A. and Hinnant, C. C.: Open data policy-making: A review of the state-of-the-art and an emerging research agenda: Introduction to a selection of open data policy-making papers from dg.02018, IP, 24, 117-129, https://doi.org/10.3233/IP-190160, 2019.

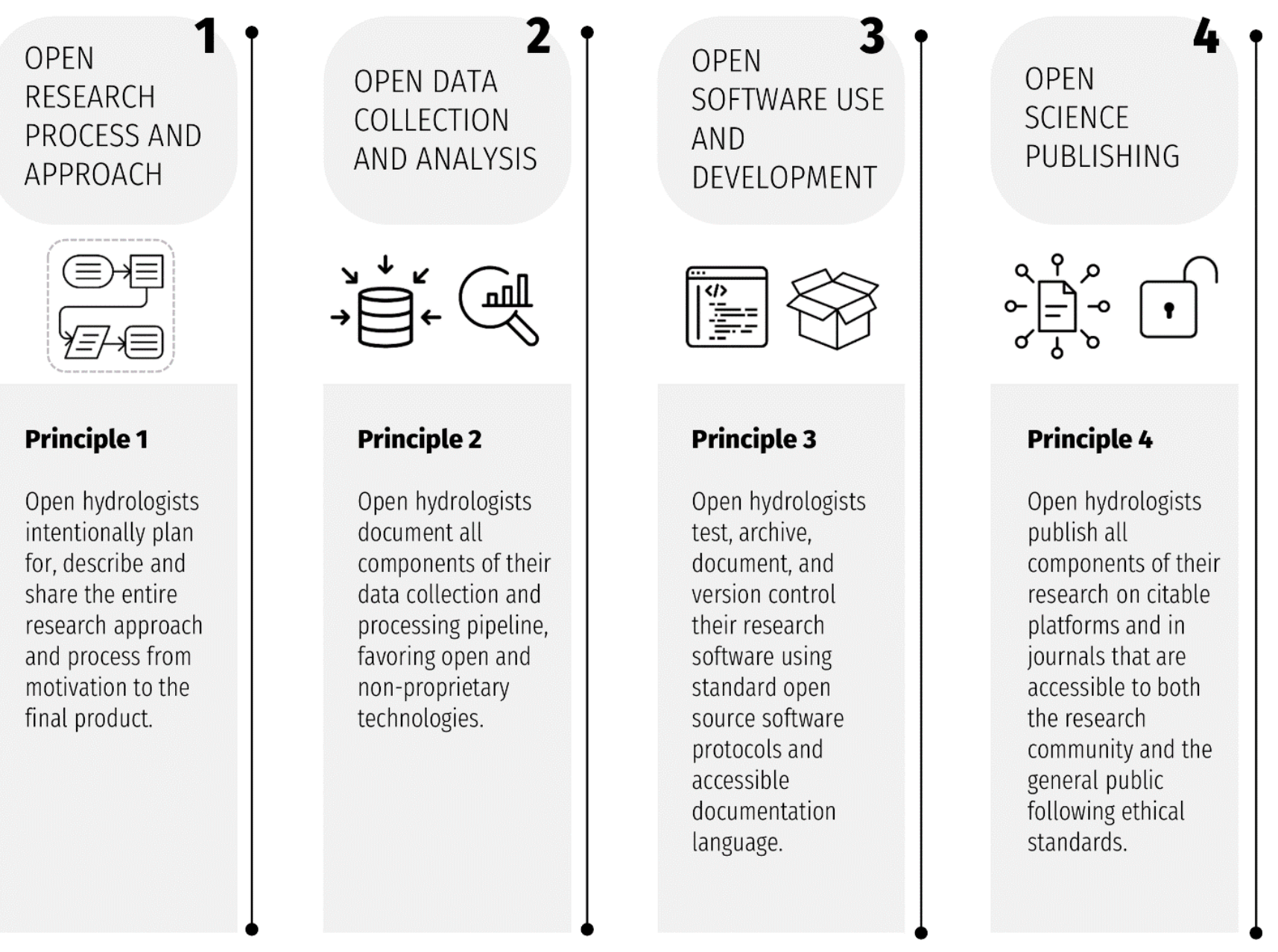

Figure 1: The Open Hydrology Principles. 
445 Table 1: A selection of efforts that discuss and support openness in hydrology and related sub-disciplines (*peer-reviewed article, **community contribution). For an up-to-date resource list, see https://open-hydrology.github.io/resources/.

\begin{tabular}{ll}
\hline Theme & Title \\
\hline The Tao of open science for ecology* \\
Enhancing Climate Change Research With Open Science* \\
Open weather and climate science in the digital era* \\
Cracking "Open" Technology in Ecohydrology* \\
The importance of open science for biological assessment of aquatic \\
environments* \\
Open Hydrology Website (established with this manuscript) \\
HydroShare is CUAHSI's online collaboration environment for \\
sharing data, models, and code. \\
Joint Editorial-On the future of journal publications in hydrology* \\
Improving the visibility of hydrological sciences from developing
\end{tabular}

Open countries*

Publishing

Assessing data availability and research reproducibility in hydrology and water resources*

Invigorating Hydrological Research Through Journal Publications*

Most computational hydrology is not reproducible, so is it really science?*

Comment on "Most computational hydrology is not reproducible, so is it really science?"

Towards a more reproducible ecology*

Elevating The Status of Code in Ecology*

Open Source

and

Reproducibility
Using $\mathrm{R}$ in hydrology: a review of recent developments and future directions*

Hydrogeological conceptual model building and testing: A review* Open science, reproducibility, and transparency in ecology*

On doing large-scale hydrology with Lions: Realising the value of perceptual models and knowledge accumulation**

Current status on the need for improved accessibility to climate models code*

Created for EGU GA short course "Using R in Hydrology"**

\section{Reference}

(Hampton et al., 2015)

(Tai and Robinson, 2018)

(de Vos et al., 2020)

(Turner et al., 2020)

(Beck et al., 2020)

https://open-hydrology.github.io/

(HydroShare, 2021)

(Blöschl et al., 2014)

(Hughes et al., 2014)

(Stagge et al., 2019)

(Quinn et al., 2020)

(Hutton et al., 2016)

(Melsen et al., 2017)

(Borregaard and Hart, 2016)

(Mislan et al., 2016)

(Slater et al., 2019)

(Enemark et al., 2019)

(Powers and Hampton, 2019)

(Wagener et al., 2020)

(Añel et al., 2021)

(Young Hydrologic Society (YHS), 2021) 
"a specific list of open hydrology-relevant projects. This list is curated from repositories that make our lives as (eco-)hydrologists easier."**

Hydrological Data and Modeling in R. This initiative was built on the EGU GA short course "Using R in Hydrology"**

Challenges and Opportunities of Open Data in Ecology*

Ecological data sharing*

Editorial - Towards FAIR and SQUARE hydrological data*

Open Data

Large-sample hydrology: recent progress, guidelines for new

datasets and grand challenges

Lessons learnt from checking the quality of openly accessible river

flow data worldwide*
(GitHub - Open-Environmental-

Science/awesome-open-

hydrology, 2021)

(ropensci/Hydrology:

CRAN

Hydrology, 2021)

(Reichman et al., 2011)

(Michener, 2015)

(Cudennec et al., 2020)

(Addor et al., 2020)

(Crochemore et al., 2020)

(Educational Resources for

Educational Resources for Hydrology \& Water Resources**

Hydrology \& Water Resources |

CUAHSI HydroShare, 2021)

(Gleeson, 2020)

(Van Loon, 2020)

(Sprenger, 2020)

(Schaefli, 2021)

Open teaching to navigate hydrology: how ready are we?**

Viglione et al., 2010

Results from a survey and implications for data policy*

(Zipper et al., 2019)

Balancing Open Science and Data Privacy in the Water Sciences*

Intergovernmental cooperation for hydrometry - what, why and

Data Exchange how?*

E-monitoring the nature of water*

The devil's in the details: data exchange in transboundary waters*

"Hydrological data and WMO Data Policy", in November 2020, as part of the WMO Data Conference**
(Dixon et al., 2020)

(Pecora and Lins, 2020)

(Mukuyu et al., 2020)

(WMO Data Conference -

Outcome Material, 2021) 


\section{Appendix A}

There are no "one-size-fits-all" open hydrology best practices because each project exists within a unique context of research inputs and outputs, institutional structures, and collaborators, each motivated by different incentives and policies in place. Challenges to practicing open hydrology may arise throughout the research process and may depend on the career stage of researchers. In general, challenges to practicing open hydrology revolve around socio-cultural, organizational, economic, technological, political, and legal themes that are listed in (A1) Table 1 (About FOSTER, 2021; Allen and Mehler, 2019). Socio-cultural challenges refer to a hydrologist's limited knowledge of, confidence in, and access to open hydrology practices and tools. Technological, organizational, and economic themes refer to challenges beyond the control of individual researchers trying to do open hydrology. For example, hydrologists may strive to do open research but be limited by unstable internet connections (i.e., technical challenge), power to advocate for publishing their work openly (i.e., organizational), or lack of funds to pay for open access publication fees (i.e., economic).

Resolving obstacles to open hydrology takes know-how and persistence since challenges can be complex. To facilitate direct practice in addressing challenges to open hydrology, we present five scenarios and outline key discussion points and recommendations. Each scenario highlights a particular career stage and addresses specific challenges listed in Table 3. These five scenarios are inspired by active learning educational materials (Learner Profiles, 2021). Researchers interested in open hydrology can use these scenarios to roleplay common challenges and brainstorm strategies with colleagues (e.g., in your lab's or department's journal club) to overcome these challenges. For each scenario, we encourage open hydrologists to ask: (1) What are the important challenges and themes highlighted in this scenario? and (2) How might I/we overcome these challenges as a lab group/department/institution/organization? We encourage open hydrologists to suggest additional challenges and scenarios that we may have missed by contributing to the living document (open-hydrology.github.io).

\section{(A1) Table 1: List of common challenges that open hydrologists may experience.}

\begin{tabular}{|c|c|c|}
\hline Number & Challenge & Categories \\
\hline 1 & $\begin{array}{l}\text { Challenges surrounding navigating open hydrology resources, which may result in a lack } \\
\text { of confidence, fear of criticism, and decreased motivation to pursue open hydrology. }\end{array}$ & Socio-cultural \\
\hline 2 & $\begin{array}{l}\text { Time spent practicing open hydrology is not supported, valued, nor rewarded and benefits } \\
\text { may not be felt. }\end{array}$ & Socio-cultural \\
\hline
\end{tabular}


Lack of community to provide technical and motivational support addressing different experience and institutional levels (i.e., research group, departmental, institutional, Socio-cultural regional, global scale).

Lack of power to advocate for open hydrology practices, e.g., resistance from senior colleagues and institutional policies.

Socio-cultural, Unrecognized privileges within the research community (e.g., technologies, publications, limited access to funds, etc.) limit equitable participation in open hydrology, which further exacerbates inequities and "gatekeeping".

Lack of proper acknowledgement or citations of open hydrology resources (e.g., open data and code), which may result in limited sharing due to the fear of being scooped or not getting credit for work.

Lack of incentive to publish iterations (i.e., lessons learned) in research approaches and null and negative results.

Political

Socio-cultural

Socio-cultural Limited documentation and sustained maintenance of publicly available data, code, etc.

Socio-cultural

Technological Limited access to technical resources and/or physical facilities that are required for practicing open hydrology (e.g., cloud computing, stable internet connection, work computer).

Technological

Technological,

Prohibition and/or restriction of open-source software installation on work computers.

Organisational,

Political

Organizational,

Lack of and/or limited funds to afford the high cost of open access publishing, which may depend on complex institutional, regional, national, and global open science factors.

Economic,

Political

Restrictions on practicing open hydrology imposed by public and private institutional rules and national policies.

Political, Legal

Need to respect and honor privacy, data sovereignty, and data governance of stakeholders and collaborators.

Legal, Political, Socio-cultural

(A1) Table 2: Scenario summary table.

\begin{tabular}{lllll}
\hline Letter & Scenario Title & Actor & Career level & Challenges \\
\hline A & Knowledge of and Support for Practicing Open Hydrology & Jaime & Early career student & $\# 1, \# 3$ \\
B & Collaborator Influence on Practicing Open Hydrology & Deniz & Established researcher & $\# 2, \# 6, \# 12$
\end{tabular}


https://doi.org/10.5194/hess-2021-392

Preprint. Discussion started: 2 August 2021

(c) Author(s) 2021. CC BY 4.0 License.

C Respecting and Upholding Stakeholder Interests

Alex

Principal investigator

\#12, \#13

D Cost of Open Publishing

Robin

Postdoc

\#4, \#11

E Promoting a Culture of Open Hydrology

Dr. Hydro

Department head

\#4, \#5, \#6, \#9

470

\section{Scenario A-Knowledge of and Support for Practicing Open Hydrology}

Jaime is a Ph.D. student studying the impacts of irrigation strategies on groundwater levels. Jaime recently saw the terms "open science", "open access", "preprints", and "open-source software" used by hydrologists they follow on Twitter. No one in Jaime's lab/department has ever mentioned these terms and Jaime does not know where to go to learn more specifics or how to participate.

Knowing where to look, how to find, and how to use open science resources are fundamental skills of any successful open hydrologist and take time to learn. When knowledge of open hydrology resources and skills is accompanied by freely accessible tools (e.g, code repositories, tutorials) and supportive communities, it becomes easier and less overwhelming to pursue open science strategies. It can be especially difficult when researchers face compounding socio-cultural challenges like Jaime in Scenario A. As an early career scientist, Jaime's ability to practice open hydrology is hampered by their limited knowledge of open hydrology resources (Challenge \#1, Table 2) and limited (local) support (Challenge \#3, Table 2). As a result, Jaime may feel overwhelmed, uncertain, and anxious about practicing open hydrology.

It is important to recognize that anyone, regardless of career stage, can become an open hydrologist. On a personal level, self-study can be an effective first step to learning about open science principles and tools. Set aside time to read papers on reproducible research, version control, etc. and practice putting what you learn into use. You can also attend free online seminars (e.g., R-Ladies Global meetups) or listen to podcasts (Podcasts, 2021; EOSC Podcast Special: Making Open Science FAIR For Researchers, 2021) to learn at your own pace. There are plenty of freely accessible resources on the web that explain basic Open Science practices (Hampton et al., 2015; Allen and Mehler, 2019; European Geosciences Union, n.d.). Another important option is to reach out to friends (including those on social media), mentors, institutional staff (e.g., librarians, data managers), and colleagues familiar with practicing open science for tips on what resources they found helpful and why. They may even be interested in giving an introductory seminar or facilitating a lab group discussion. It may also help to engage with other like-minded early career scientists during institutional or professional society meetings. This way you can learn from one another and support each other's open hydrology initiatives, like https://open-hydrology.github.io.

\section{Scenario B-Collaborator Influence on Practicing Open Hydrology}

Deniz is an established hydrologist working at a government agency and is co-advising a Master's student in ecohydrology at a nearby university. In a recent committee meeting, the Master's student asked Deniz to post a preprint of their paper after it is submitted to the journal for review. The Master's student also asked if Deniz knew of places where they could post the dataset from their study upon acceptance to the journal. Deniz has an agency 
colleague with experience publishing datasets but was worried that preparing the datasets for publication might take the Master's student too much time. Also, Deniz needed to check if it was against agency policy to publish the paper before it was peer-reviewed. Not to mention, what if the non-peer-reviewed results were scooped by other scientists or used prematurely by decision-makers?

In Scenario B, a combination of socio-cultural, political, and legal challenges may come into play when practicing open hydrology at different career stages. Open hydrologists will likely encounter collaborators who are less supportive about practicing open hydrology. Limited enthusiasm may present itself throughout the research process, from sharing data and code to posting preprints, to paying for open access fees, and more. In Scenario B, Deniz's concern may be that time spent documenting and publishing data will outweigh long-term benefits (Challenge \#2, Table 2), like the increased research exposure and citations associated with open science. Fear of being scooped-when one researcher group publishes work before another doing similar work (Challenge \#6, Table 2) - is a common reason for limited participation in open science (Laine, 2017). As Deniz supposes, research staff may also be subject to government agency policies that limit their ability to practice open hydrology (Challenge \#12, Table 2).

Research supervisors and supervisees both play a critical role in the promotion and practice of open hydrology. If you are a supervisor, explicitly discuss and incorporate aspects of open hydrology into new, ongoing, and completed research collaborations to ensure research transparency. By keeping an open mind and candidly discussing practicing open hydrology when approached by your supervisee, a solution that addresses your and your supervisee's concerns and aspirations can be found. If you are a supervisee, provide your valid arguments for open hydrology, while still being considerate of your supervisor's concerns and honoring potential policies limiting open practices. One point to address can be highlighting the potential long-term impact of open hydrology on your career (Allen and Mehler, 2019). Another approach might be to ask established open hydrologists to discuss with you and your supervisor their points of hesitation. For both supervisors and supervisees, reflect on each aspect of your research pipeline and how each adheres to open hydrology principles. Start with small changes and sustainably build on your open hydrology practices with each new project (Allen and Mehler, 2019). Furthermore, advocate for policy changes and long-term perspectives that value open hydrology practices. Time and effort dedicated to making research more open is not a loss because it will benefit current and future research collaborators, stakeholders, and society.

\section{Scenario C-Respecting Stakeholder Interests}

Alex is a principal investigator conducting a sociohydrology research project in collaboration with local stakeholders who hold diverse beliefs on a particular issue impacting the region. Alex has had in-depth conversations with these stakeholders and all members of the project have agreed to participate in an anonymous survey that will assess their perspectives on the regional issue. In this project, Alex must protect personally identifying information when sharing results. Furthermore, Alex and the stakeholders have come to an agreement 
https://doi.org/10.5194/hess-2021-392

Hydrology and

Preprint. Discussion started: 2 August 2021

(c) Author(s) 2021. CC BY 4.0 License.

on specific data outputs and use cases that can be shared publicly; all other data and use cases are property of the stakeholders.

Since an increasing amount of hydrology research is conducted in collaboration with stakeholders, it is important to respect the rights and requests of these stakeholders (Challenge \#13, Table 2), maintain stakeholder privacy (Challenge \#12, Table

2), and adhere to research sharing agreements. In Scenario C, Alex must navigate a combination of political, legal, and socio-cultural challenges when conducting transdisciplinary hydrology research alongside communities.

Open hydrologists can consider several strategies to uphold their commitment to transparency and reproducibility while respecting the rights and policies of their collaborators. Project leaders have a fundamental responsibility to spend time developing an open research plan with collaborators and stakeholders that describes public versus private research outputs, use cases, and what will be shared to whom and when. Importantly, all impacted community members must co-produce this open research plan with the research team and consent to data collection, analysis, and dissemination. You can look at standard privacy guidelines, including the General Data Protection Regulation (General Data Protection Regulation (GDPR), 2021) and data governance and data sovereignty principles (Carroll et al., 2020). Principle 2 discusses how to document decisions made and protocols around public research sharing so others can refer to this context and guidance can be found with the United Nations GEMStat program (Data protection GDPR, 2021). You may be able to share anonymized data such as metadata that does not indicate water quality issues for a specific geographic region.

\section{Scenario D—Cost of Open Publishing}

Robin recently defended their Ph.D. thesis and started a postdoctoral researcher position. In their free time, Robin is finishing up an irrigation water management project that they worked on alongside agricultural producers during their Ph.D. research. Robin will present these findings to agricultural producers during a virtual webinar and wants to publish these findings in an open access journal article, so it is easier for people outside academia to find and read. However, Robin does not have enough grant funds to cover the expensive open access fees and feels uncomfortable asking their postdoctoral advisor, who is in a different sub-hydrology field, for these funds.

Scenario $D$ illustrates how distressing the lack of extra funds needed to pay open access publication fees (Challenge \#11,

555 Table 2), which is a common concern when practicing open hydrology. This scenario can be exacerbated when early career open hydrologists, like Robin, are transitioning between positions and projects and/or have limited power and resources to advocate for covering the cost of these fees (Challenge \#4, Table 2). This inability to cover the cost influences the impact of the research because open access publications tend to be cited more (Wang et al., 2015) and are assuredly accessible to research partners and the general public. Open access publishing is a common and effective starting point for practicing open hydrology. Beyond challenges posed by being early in one's career stage, economic, political, and organizational challenges may hamper efforts by researchers of all experience levels from developing countries.

To overcome the challenges outlined in Scenario D established open hydrologists can start as early as possible in the research process to plan for open access publishing. The easiest solution is to look for an OA journal that does not charge an 
Article Processing Cost (APC) to the authors or any of the authors' institutions. You can budget funds to cover the cost of government agencies can retain the copyrights to their publications. More specifically, journals have special provisions to allow them to share the journal formatted paper without infringing on the journal's copyright laws. However, you should check the policies for each journal as the corresponding author may have to be from the government agency and/or several co-authors may also have to be from a government agency to qualify. In other cases, journals waive fees and/or discounts to researchers from certain countries or per individual requests. You can also check the journal website and publisher's policy to learn about your institution's or country's eligibility conditions. If you are an early career open hydrologist who was not present at the start of the research project, you can discuss the possibility of open access publishing with your supervisor. Some libraries and institutions have dedicated supplemental funds to support researchers who choose to publish their papers as open access. If all else fails, researchers typically can post a plain copy of the journal article on a non-for-profit preprint server (e.g., EarthArXiv). This can be done at any stage of paper preparation, but all corresponding authors need to agree to post the preprint.

\section{Scenario E-Promoting a Culture of Open Hydrology}

Dr. Hydro is the faculty chair of an environmental sciences department and is providing mentorship and departmental support (e.g., funding for open access and technology fees, honors to researchers doing open science) to several graduate students and faculty members in the department who have started organizing discussion groups and developing training materials to promote short-and long-term open science practices within their research groups. Some members of the department feel like this is a waste of time, but Dr. Hydro thinks these are important initiatives that will benefit the members of their department and beyond, especially in the long term.

Unlike Scenarios A-D, Scenario E represents an example of a senior researcher supporting open hydrology efforts at their institute. Open science is a cultural movement, which ought to find deep roots in the hydrology community given the potential impact of our work on society. However, promoting a culture of open science requires individual- and communitybased responsibility. We are each a part of a cultural shift towards open hydrology. At the individual level, researchers' roles in open hydrology are crucial and diverse. In Scenario E, Dr. Hydro strives to overcome socio-cultural, technological, and political challenges to promote open hydrology in their department, institution, and beyond. Specifically, Dr. Hydro uses their position (i.e., power) as a department chair to advocate for open hydrology practices (Challenge \#4, Table 2), ensures that all members of the department have equitable opportunities for practicing open hydrology (Challenges \#5 and \#9, Table 2), and promotes and honors community-driven open hydrology initiatives in the department (Challenge \#6, Table 2). Although this might seem like a huge challenge at the beginning, Dr. Hydro is convinced that these efforts will not only benefit the hydrologists at their institute but ultimately the entire field of hydrology, and society. 
https://doi.org/10.5194/hess-2021-392

Preprint. Discussion started: 2 August 2021

(c) Author(s) 2021. CC BY 4.0 License.

595 Researchers interested in practicing open hydrology can organize or attend regular seminars or journal clubs, while early to established researchers can learn about open science principles and ways to apply them to their work. Such a space can serve as a platform to discuss open hydrology, brainstorm solutions for common issues that are encountered. If you are a principal investigator of a research group, you can play an important role in promoting open hydrology by establishing guidelines for your trainees. Finally, students, staff, and faculty can all promote the use of open-source software like R, Python, or QGIS 600 for hydrology research and participate in local, regional, national, and global efforts to sport open science. 